\title{
Panorama do setor eólico no estado do Rio Grande do Norte no período 2004-2017
}

GERBESON CARLOS BATISTA DANTAS, ${ }^{I}$ MARCUS VINÍCIUS SOUSA RODRIGUES, II LEONARDO MAGALHÃES XAVIER SILVA, III MARISETE DANTAS DE AQUINO ${ }^{I V}$ e ANTÔNIO CLÉCIO FONTELLES THOMAZ ${ }^{V}$

\section{Introdução}

A ENERGIA eólica pode ser definida como a energia proveniente das correntes de ar que circulam pela atmosfera devido ao seu aquecimento desigual. É uma energia considerada limpa, renovável e disponível em todos os lugares (Alves, 2010; Rodrigues et al., 2015). Inicialmente, a energia eólica foi utilizada por meio dos antigos moinhos de ventos para a realização de trabalho mecânico, como na drenagem de água e na moagem de grãos.

No final do século XIX, os moinhos de vento passam a ser projetados para gerar eletricidade. Conforme Hamdan et al. (2014), a aplicação da energia eólica para geração de eletricidade só teve um forte desenvolvimento a partir dos anos 1970 com a crise do petróleo. Na atualidade, pode-se afirmar que a energia eólica vem sendo utilizada quase que exclusivamente para a geração de energia elétrica.

Além do benefício de seu uso para a geração elétrica, a energia eólica não apresenta riscos de emissão de radiação e depende de uma fonte de energia livre. Outra vantagem da energia eólica refere-se ao fato de que ela não contribui significativamente para a emissão de $\mathrm{CO}^{2}$, principal Gás do Efeito Estufa (GEE) (Carneiro et al., 2013). De acordo com Oebels e Pacca (2013), a emissão de $\mathrm{CO}_{2}$ da energia eólica está concentrada, majoritariamente, na fase de fabricação e, secundariamente, nas fases de manutenção e transporte. Já as fases de construção e operação não apresentam contribuição significativa. O estágio final de vida útil também apresenta contribuição insignificante, pois um alto percentual de geradores de energia eólica é reciclado (Oebels; Pacca, 2013). 
Segundo Vogel et al. (2018), Jung e Schindler (2018), Melo (2013), esse conjunto de vantagens fará que a energia eólica desempenhe um papel cada vez mais expressivo na geração de energia em todo o mundo, tanto para atender as demandas futuras por eletricidade, como para mitigar as alterações climáticas provocadas pela emissão de GEE.

O equipamento que a converte em energia elétrica é a turbina eólica, também conhecida como aerogerador ou sistema conversor de energia eólica. De acordo com Shamshirband et al. (2014), a energia cinética do vento captada pela turbina eólica é função da velocidade do vento, da massa específica do ar, da área de varredura das pás e da eficiência do equipamento.

As máquinas eólicas modernas são classificadas de acordo com o eixo ao redor do qual as pás da turbina giram. Assim, são classificadas em duas categorias: as turbinas eólicas de eixo horizontal - TEEH (ou HAWT - horizontal axis wind turbine) e as turbinas eólicas de eixo vertical - TEEV (ou VAWT vertical axis wind turbines).

Segundo Leung e Yang (2012), parque eólico (também chamado de fazenda eólica) pode ser definido como um conjunto de turbinas eólicas instaladas em uma determinada área e ligadas a uma rede de transmissão de energia. É importante ressaltar que a maioria das turbinas eólicas instaladas nos parques eólicos para geração de energia elétrica são TEEH. A tecnologia de instalação dessas máquinas para geração de eletricidade pode ser onshore (em terra) ou offshore (no mar).

Em razão de seu favorecimento de ventos, o Brasil apresenta um potencial eólico bastante representativo e que ainda pode ser muito explorado e expandido como alternativa para a geração de energia elétrica. Para essa finalidade, a região Nordeste se destaca das demais regiões do país. Para Juárez et al. (2014), a região tem atraído investimento estrangeiro na construção de parques eólicos, subsidiados pelo Banco Nacional de Desenvolvimento Econômico e Social (BNDES).

É importante destacar que o Nordeste é a região do país que apresenta a maior capacidade para geração de energia eólica, razão pela qual a maioria dos empreendimentos eólicos em operação no Brasil concentra-se nos estados nordestinos, sendo o Rio Grande do Norte $(\mathrm{RN})$ o estado responsável pela maior parte de toda a capacidade instalada no território brasileiro, conforme dados da Associação Brasileira de Energia Eólica (ABEEólica, 2017a).

Nesse contexto promissor, o objetivo principal deste trabalho consiste em realizar um panorama do setor de energia eólica do estado do Rio Grande do Norte, desde o início do processo de implantação dos primeiros parques eólicos em 2004 até o ano 2017, mostrando a força do estado na geração de energia elétrica proveniente dos ventos.

A metodologia aplicada nesta pesquisa consiste em uma pesquisa em vasto material bibliográfico, disponibilizado em publicações (livros, artigos, periódicos 
e trabalhos acadêmicos) e também em páginas eletrônicas relacionadas, direta ou indiretamente, ao setor de energia eólica.

\section{A energia eólica no Brasil}

Segundo a Agência Nacional de Energia Elétrica (Aneel, 2008), a primeira experiência com energia eólica no Brasil ocorreu em 1992 com a instalação da primeira turbina eólica comercial, instalada no arquipélago de Fernando de Noronha, no estado de Pernambuco (PE). Porém, ressalta Ferreira Júnior e Rodrigues (2015), pouco se avançou nos dez anos seguintes para a consolidação do setor eólico como fonte alternativa de geração elétrica no país.

Somente no ano 2002, um ano após a crise energética de 2001, é que houve uma tentativa de incentivar a contratação de energia eólica no Brasil, com a criação do Programa de Incentivo às Fontes Alternativas de Energia Elétrica (Proinfa). Esse programa foi instituído por meio da Lei Federal n.10.438, de 26.4.2002, e revisado pela Lei Federal n.10.762, de 11.11.2003, e, posteriormente, regulamentado pelo Decreto Federal n.5.025, de 30.3.2004. Conforme Pereira et al. (2013), o programa favoreceu o crescimento da produção de energia eólica no Brasil, de 22 MW em 2003 para 602 MW no início do ano de 2010.

O Brasil, no cenário mundial, se destaca, uma vez que apresenta uma matriz de geração de energia elétrica baseada em fontes renováveis, em que predomina a hidroeletricidade e a biomassa proveniente da cana-de-açúcar (Bezerra; Santos, 2017).

Assim, pode-se afirmar que o Brasil apresenta um dos perfis tecnológicos energéticos mais limpos do mundo, de modo que as fontes renováveis representam cerca de $80,9 \%$ da matriz nacional, conforme é possível observar nos dados apresentados na Figura 1.

De toda a potência instalada para geração de eletricidade no Brasil, cerca de $8,1 \%$ provêm da fonte eólica. A matriz eólica apresenta uma potência instalada em parques eólicos de aproximadamente 12,77 GW. Vale salientar que. apesar de a capacidade, em termos percentuais, ser modesta, o Brasil é o líder da América Latina na produção dessa fonte de energia (ABEEólica, 2017a).

Segundo Global Wind Energy Council (GWEC, 2017), em termos globais, os países campeões em uso da energia eólica para gerar eletricidade são a China, os Estados Unidos e a Alemanha, que ocupam respectivamente as três primeiras posições em capacidade instalada, enquanto o Brasil ocupa somente a nona posição, com $2 \%$ de toda potência instalada ao redor do globo. No que se refere a potência eólica instalada em 2017, o Brasil sobe para sexto lugar no ranking internacional, totalizando $4 \%$ do contingente.

Pode-se afirmar que essa posição ocupada pela Brasil é bastante tímida, entretanto, pela sua grande extensão territorial e sua excelente potencialidade para geração eólica, em razão dos seus ventos, em especial na região Nordeste, o país ainda pode avançar muito nos próximos anos e para isso faz-se necessárias políticas governamentais e incentivos no setor. 


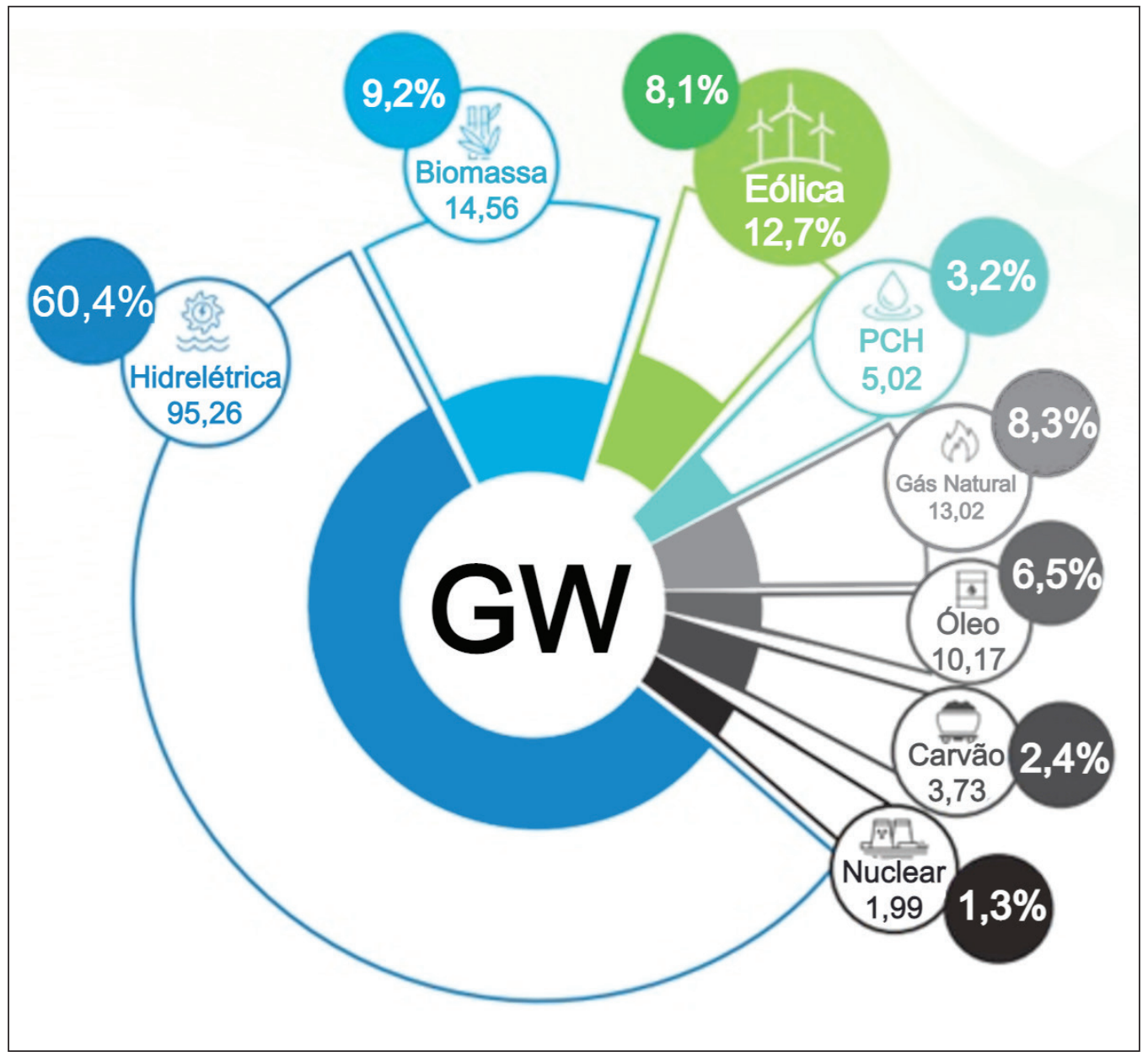

Fonte: ABEEólica (2017a).

Figura 1 - Perfil tecnológico brasileiro em 2017.

O Brasil é um dos países que mais investem em tecnologia para geração de energia elétrica a partir dos ventos, especialmente nos estados nordestinos, e atualmente a energia eólica está enfrentando a maior taxa de crescimento nos últimos anos.

Atualmente, o país conta com um total de doze estados produtores de energia eólica, sendo oito localizados no Nordeste. Em seguida, no Gráfico 1 são apresentados o número de parques eólicos em operação e a potência instalada em cada estado brasileiro que gera energia elétrica a partir dos ventos.

Os dados apresentados no Gráfico 1 demonstram a força da região nordestina em se tratando de geração eólica. Isto é, dos 503 parques eólicos em operação em todo o território nacional, 407 se encontram no Nordeste, que juntos apresentam uma capacidade instalada de 10,72 GW, representando cerca de $84 \%$ de toda a capacidade do país (ABEEólica, 2017b). 


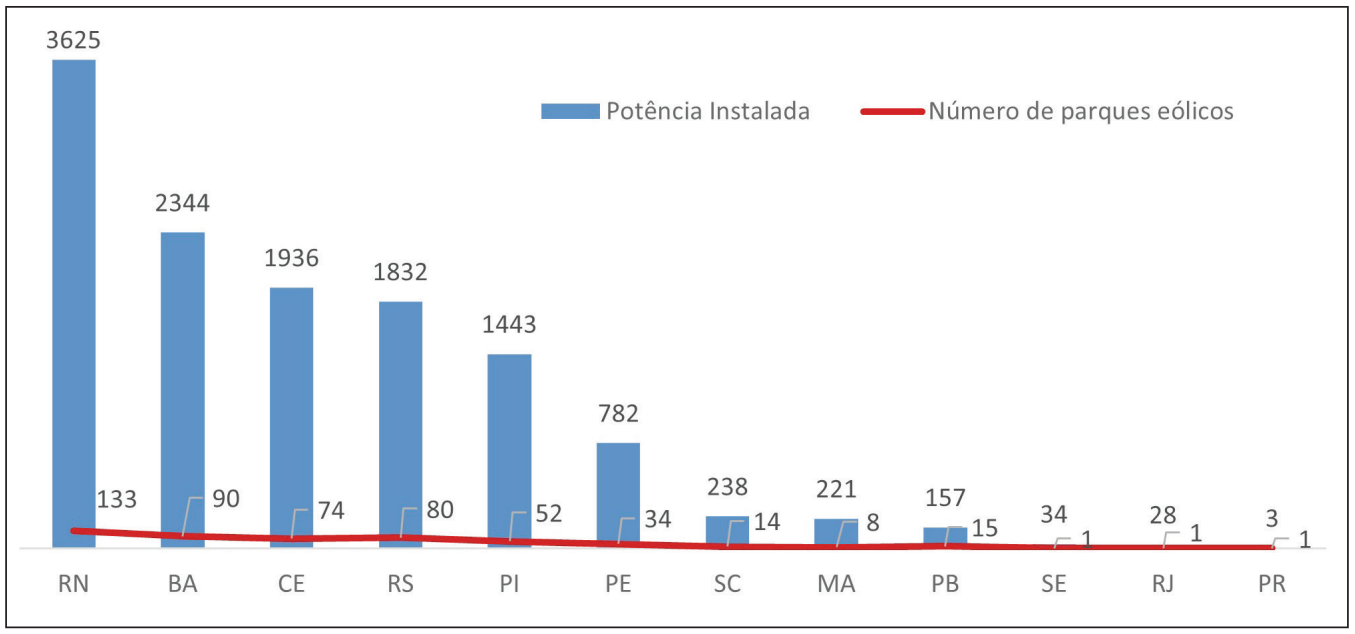

Gráfico 1 - Número de parques eólicos em operação e a potência instalada, em MW, em cada estado brasileiro produtor de energia eólica em 2017. Fonte: Adaptado de ABEEólica (2017b).

A região Nordeste pode ser considerada área de destaque para a produção de energia eólica, especialmente na sua extensa faixa litorânea. Segundo Lira et al. (2014), os estados de Maranhão, Piauí, Ceará e Rio Grande do Norte são favorecidos pela combinação de ventos do leste com brisas marítimas e terrestres, levando a média anual da velocidade do vento em torno de 6 a $9 \mathrm{~m} / \mathrm{s}$.

Jong et al. (2016) salientam que a geração de energia eólica nos estados do Nordeste, em especial Ceará, Bahia e Rio Grande do Norte, tende a continuar a crescer significativamente nas próximas décadas.

O crescimento da energia oriunda dos ventos na matriz brasileira de energia tem trazido ganhos significativos ambientais, sociais e econômicos (Silmas; Pacca, 2013). Estima-se que o total de emissões de $\mathrm{CO}_{2}$ evitadas em 2017 foi de 20, 97 milhões de toneladas, equivalente à emissão anual de cerca de 16 milhões de automóveis. Em relação aos investimentos, o ano 2017 encerrou com US\$ 3.57 bilhões investidos no setor eólico. No período entre 2010 e 2017, esse número chega a US\$ 32 bilhões, proporcionando geração de empregos com salários qualificados e arrecadação de impostos para os estados. Outro número promissor é o total de residências atendidas por mês, cujo estimativa bateu o recorde de 22,4 milhões de residências, totalizando a marca de 67,2 milhões de pessoas (ABEeólica, 2017a).

\section{A energia eólica no estado do Rio Grande do Norte}

Localizado no extremo Nordeste do Brasil, o estado do Rio Grande do Norte está situado entre os paralelos 6 $58^{\prime} 57^{\prime \prime S}$ e $4^{\circ} 49^{\prime} 53^{\prime \prime} \mathrm{S}$ e os meridianos $38^{\circ} 34^{\prime} 54^{\prime \prime} \mathrm{W}$ e $34^{\circ} 58^{\prime} 08^{\prime \prime} \mathrm{W}$, na região Nordeste do Brasil, fazendo divisa com o Oceano Atlântico, a norte e a leste; com o estado do Ceará, a oeste; e com o estado da Paraíba, a sul (Cosern, 2003), conforme ilustrado na Figura 2. O 
estado ocupa uma área de $53.307 \mathrm{~km}^{2}$, o que representa cerca de $0,62 \%$ do território brasileiro.

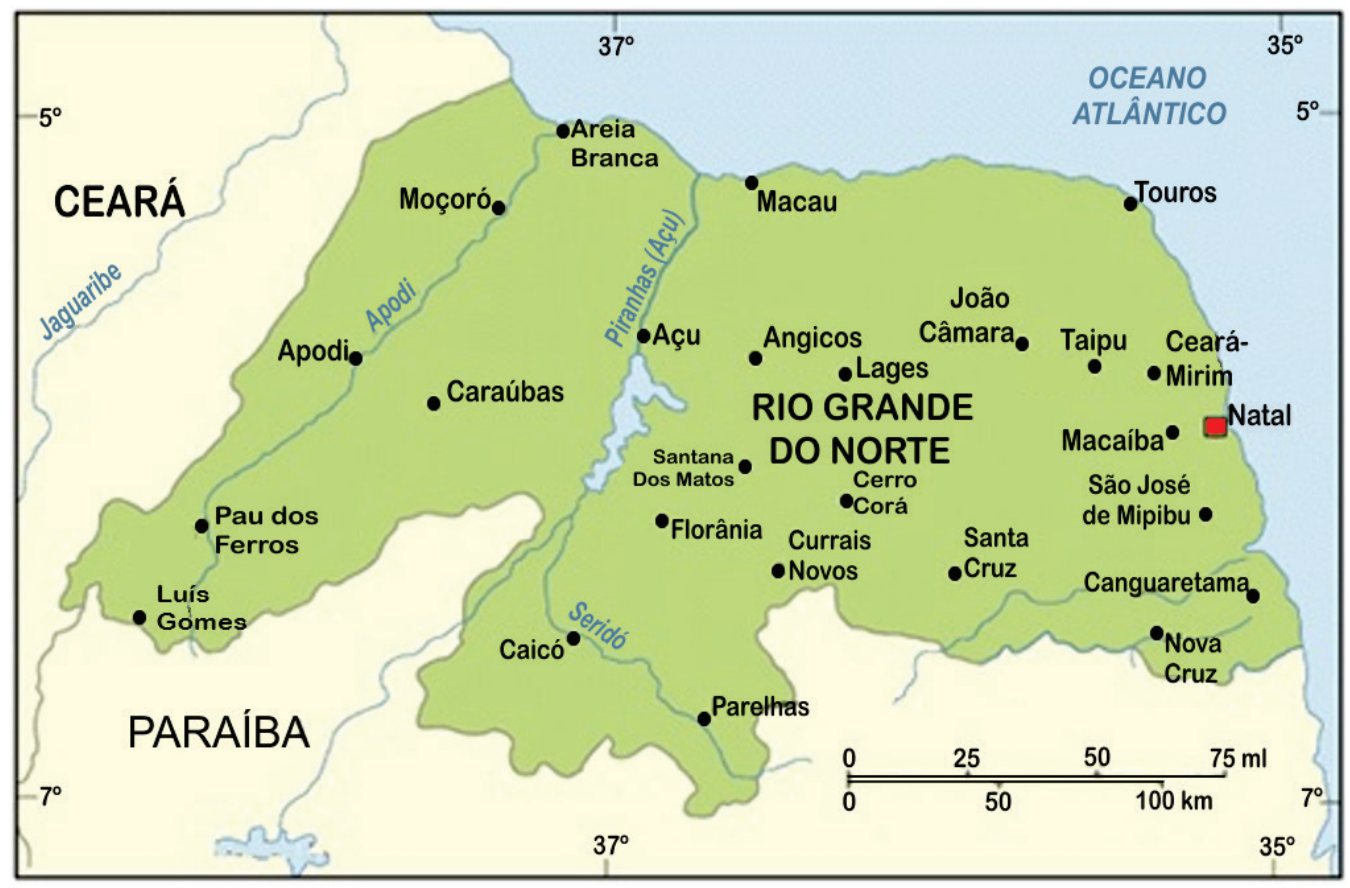

Fonte: GuiaNet.

Figura 2 - Localização geográfica do estado do Rio Grande do Norte.

O estado do Rio Grande do Norte caracteriza-se por um clima quente semiárido na maior parte do seu território, e segundo Rodrigues e Aquino (2013), 93\% do seu território estão inseridos no semiárido, passando a quente semiúmido em sua porção litorânea oriental, ao sul do Cabo de São Roque. A localização geográfica do estado do Rio Grande do Norte favorece muito a ação de correntes de ventos tanto em seu litoral como em boa parte de seu interior, e como resultado, o estado apresenta um relevante potencial eólico para investimentos na geração de energia elétrica a partir de seus ventos.

É possível afirmar que o estado tem os melhores ventos do território brasileiro para a instalação de parques eólicos para a geração de energia elétrica. É importante destacar que o regime de ventos no estado apresenta uma grande sazonalidade com a ocorrência de ventos mais intensos nos meses de agosto a novembro, e mais brandos nos meses de fevereiro a maio.

O Atlas do Potencial Eólico do estado do Rio Grande do Norte foi publicado no ano 2003 e foi resultado da iniciativa da Companhia Energética do Rio Grande do Norte (Cosern), em seu programa de Pesquisa e Desenvolvimento, com o suporte da Iberdrola Empreendimentos do Brasil S. A. (Ibenbrasil). Nesse documento são mostrados os principais parâmetros estatísticos 
de velocidade e direção dos ventos para todo o território potiguar (Cosern, 2003).

O primeiro empreendimento eólico para geração de energia elétrica do estado do Rio Grande do Norte foi o parque eólico construído pela Petrobras, apenas para autoconsumo, em 2004, no município de Macau, distante $188 \mathrm{~km}$ da capital do estado. O parque possui três turbinas eólicas, com capacidade de $600 \mathrm{~kW}$ cada uma, totalizando 1,8 MW de potência instalada (Azevedo et al., 2015).

Em seguida, no ano 2006 é inaugurado o segundo parque eólico do estado, no município de Rio do Fogo, distante $81 \mathrm{~km}$ de Natal. O parque Rio do Fogo apresenta 62 turbinas eólicas, com capacidade de $800 \mathrm{~kW}$ cada uma, o que totaliza 49,6 MW de potência instalada para o parque.

Conforme Azevedo et al. (2015), a produção de energia eólica no Rio Grande do Norte só se tornou expressiva no ano 2009, quando por meio de dois leilões distintos foi contratada a implantação de 32 parques eólicos no estado. Ao final do ano de 2010, o estado possuía apenas três parques eólicos em operação, totalizando uma potência instalada de aproximadamente 102,4 MW.

Em agosto de 2010 entra em operação o parque eólico Alegria I, instalado na praia do Minhoto, no município de Guamaré, distante $175 \mathrm{~km}$ da capital potiguar. O parque eólico apresenta 31 turbinas eólicas em operação, com uma capacidade instalada de 51,0 MW. O parque faz parte de um complexo eólico, juntamente com o parque eólico Alegria II, que apresenta 61 turbinas eólicas operando, com uma capacidade instalada de $101 \mathrm{MW}$.

Assim, ao final do ano 2010 o Rio Grande do Norte possuía apenas três parques eólicos em operação, totalizando uma potência instalada de aproximadamente 102,4 MW. É importante salientar que em razão do relevante potencial de geração de energia elétrica por meio dos ventos no estado, somado ao incentivo às fontes de energia renováveis para diversificar a matriz energética nacional, foi possível ao estado atrair para si investimentos no setor eólico desde 2010.

Em 2011 o governo do estado publica o Plano de Ação em Ciência, Tecnologia e Inovação do Estado do Rio Grande do Norte (Pacti), que previa, dentre outras ações, a criação de um Centro Internacional de Tecnologia em Energia Eólica até o final de 2015, o que favoreceria pesquisas no desenvolvimento de tecnologias eólicas (Rio Grande do Norte, 2011).

O Pacti incentivou a pesquisa e inovação no setor eólico, o que acarretou um salto na produção eólica nesses últimos seis anos, atingindo uma potência instalada de aproximadamente 3,4 GW ao final de 2016. O Gráfico 2 apresenta uma ilustração da evolução do setor eólico desde o ano 2011 até o final do ano 2016 em que sem observa um crescimento significativo, tanto em número de parques eólicos em operação como em capacidade instalada. 


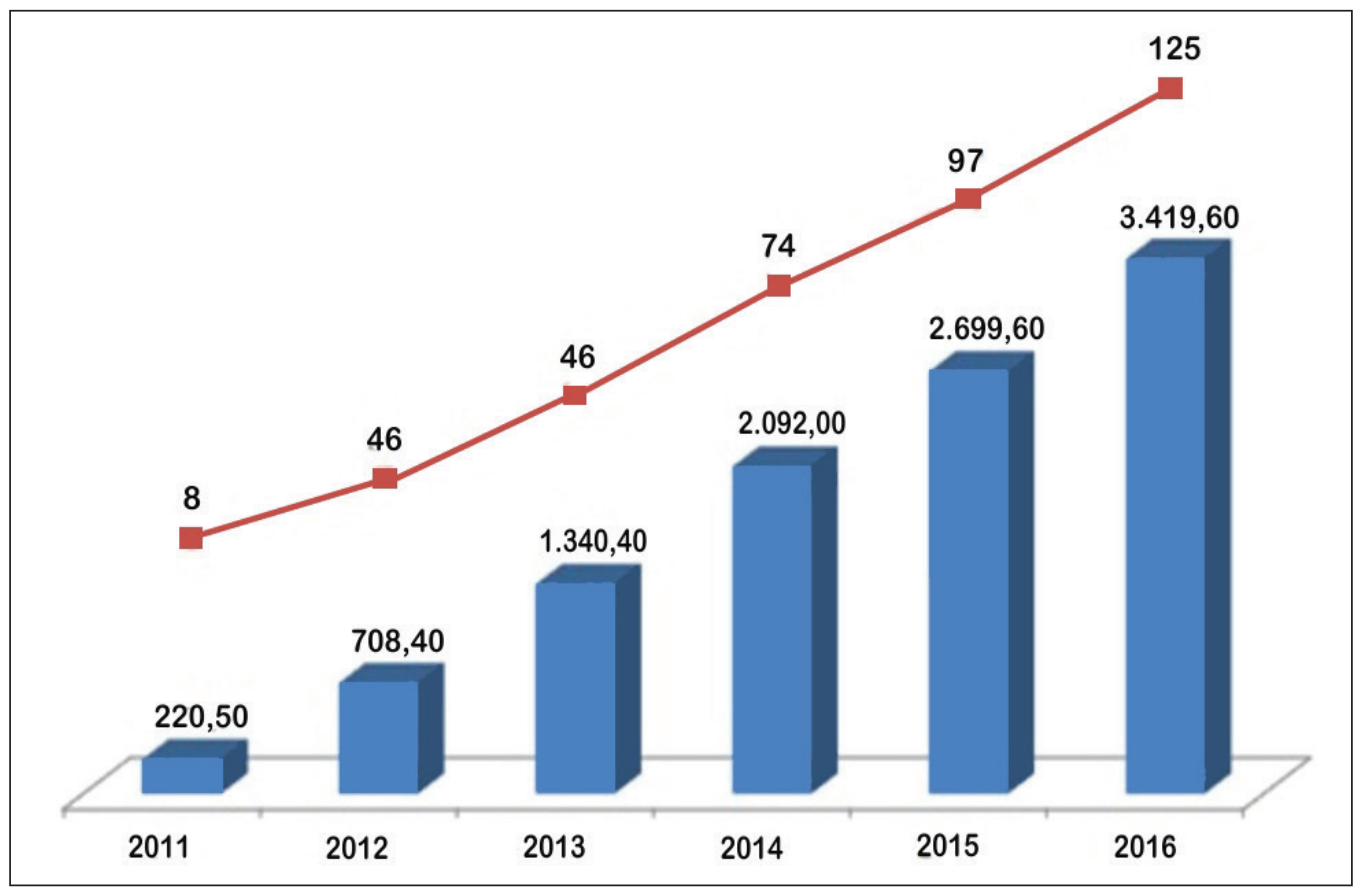

Fonte: Adaptado ABEEólica (2016).

Gráfico 2 - Evolução ao longo dos anos do setor eólico no estado do Rio Grande do Norte.

O mercado eólico do Rio Grande do Norte passou por uma significativa e importante transformação em pouco mais de uma década, desde o início dos investimentos na implantação de parques eólicos em 2003 até os dias atuais. Ou seja, o setor eólico está em plena expansão do seu potencial impulsionado pelos investimentos na área, tais como a construção de parques eólicos, e pelas pesquisas em geração de energia eólica. Como resultado, a capacidade instalada em todo o estado cresceu significativamente nos últimos cinco anos.

No início do ano 2016, o estado potiguar contava com um total de 97 parques eólicos em operação em seu território, com 2.699,6 MW de potência instalada. Entretanto, ao longo do ano 2016, um total de 28 novos parques eólicos entrou em operação, aumentando em 720,2 MW a capacidade instalada do território, atingindo assim uma potência total de 3.419,8 MW, instalada em 125 parques eólicos. Assim, ao longo de 2016 a potência instalada no estado do Rio Grande do Norte teve um crescimento de aproximadamente 22,6\%.

Durante o ano 2017, até o fim do mês de setembro, mais seis novos parques eólicos entraram em operação no estado, atingindo assim uma potência de 3.585,6 MW em todos os 131 parques em operação. Em dezembro esse número subiu para 3.625,50 MW em 133 parques em operação. De acordo com ABEEólica (2017b), estão em construção 36 novos parques eólicos, com uma capacidade de 887,8 MW. 
Filgueiras e Silva (2003) ressaltam o fato de que a potência instalada não é igual à energia produzida, uma vez que as turbinas eólicas são equipamentos que apresentam eficiência limitada em 59\%, conforme Lei de Betz. Dessa forma, é possível concluir que a energia eólica gerada no estado é bem inferior à capacidade total instalada em todo território.

O estado se destaca no cenário nacional de energia eólica como o maior produtor de energia elétrica por intermédio dos ventos durante o ano de 2017 , conforme pode ser visto na Tabela 1 , em que são apresentados os cinco estados brasileiros com maior geração, em TWh $(1,0 \mathrm{TWh}=1.000 .000,0 \mathrm{MWh})$.

Tabela 1 - Energia gerada nos estados que ocupam as cinco primeiras posições durante 2017

\begin{tabular}{|c|c|c|}
\hline Posição & Estados & Energia gerada (TWh) \\
\hline $1^{\mathrm{a}}$ & Rio Grande do Norte & 13,24 \\
\hline $2^{\mathrm{a}}$ & Bahia & 7,79 \\
\hline $3^{\mathrm{a}}$ & Rio Grande do Sul & 5,58 \\
\hline $4^{\mathrm{a}}$ & Ceará & 5,10 \\
\hline $5^{\mathrm{a}}$ & Piauí & 4,59 \\
\hline
\end{tabular}

Fonte: ABEEólica (2017a).

Conforme a ABEEólica (2017a), a região Nordeste gerou ao todo, no ano 2017, aproximadamente 33,99 TWh de energia, o que representa cerca de $84 \%$ de toda a energia eólica gerada no Brasil, que foi igual a 40,46 TWh. Esses números representaram um crescimento significativo. Em 2016, a geração total brasileira foi de 32,07 TWh, resultando em uma variação de $26,2 \%$ em relação a 2017. No que tange à região Nordeste, a geração cresceu 25\% em 2017. Já a produção de energia eólica pelos parques eólicos em operação comercial no Rio Grande do Norte representou 38,95\% de toda a geração eólica do Nordeste e $32,72 \%$ da geração eólica brasileira no ano de 2017. Isso mostra a relevância do setor eólico no estado potiguar.

Em seguida, no Gráfico 3, são apresentados para cada mês do ano de 2017 os valores mensais de geração (em MW médio) de energia eólica nos parques eólicos do estado. Conforme o dado apresentado no Gráfico 3 é possível observar que a maior média mensal ocorreu no mês de setembro, que gerou em média 2.227,70 MW médios, enquanto a menor média mensal aconteceu no mês de março, em que foi gerado 852,5 MW médios de energia eólica. A geração elevada entre os meses de agosto e setembro é justificada pela safra do vento. Esse fenômeno ocorrido nestes meses proporcionou uma marca recorde: pela primeira vez a energia elétrica gerada pela força do vento mensal foi superior a $10 \%$ da média do total de geração (ABEEólica, 2017a). 


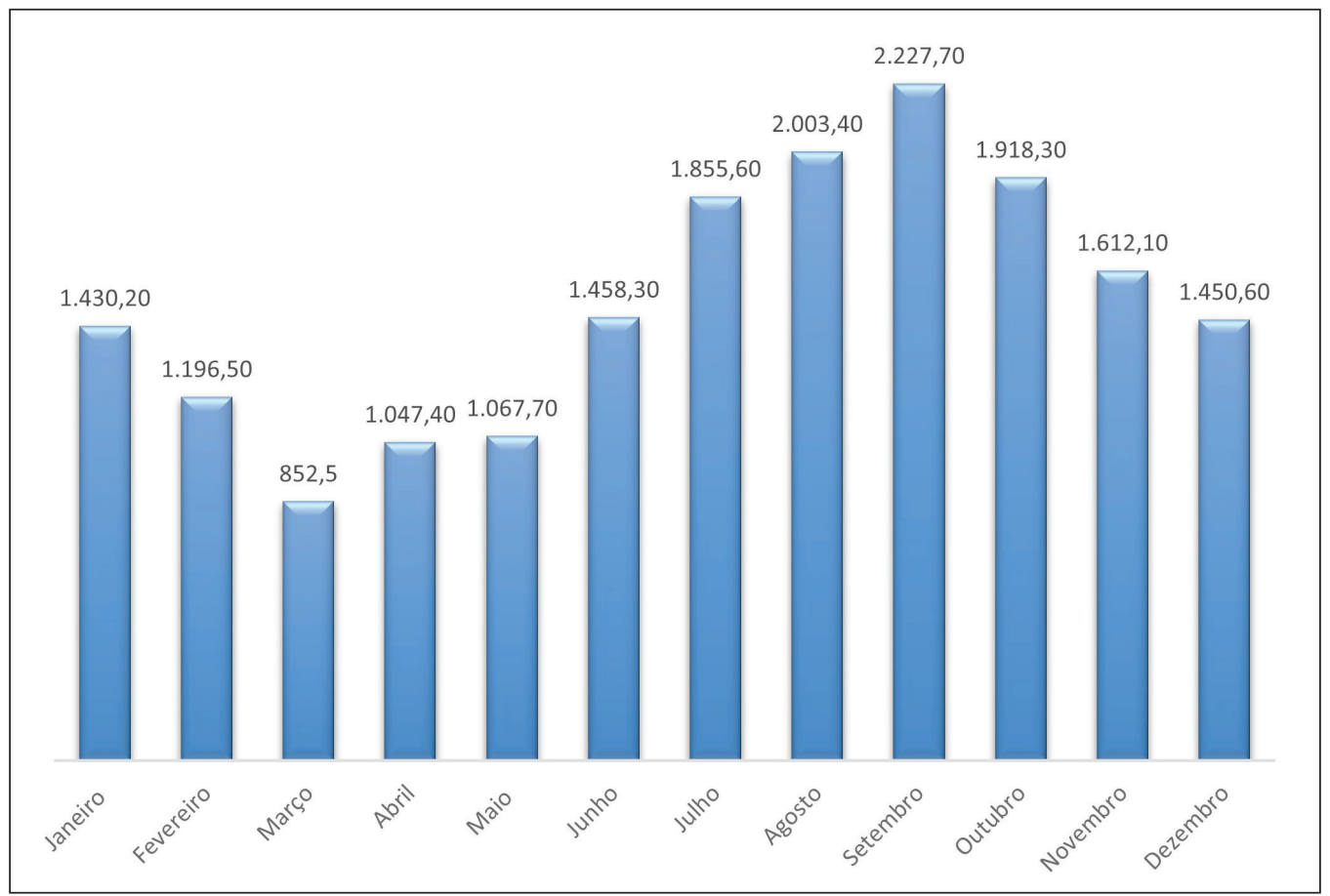

Fonte: Adaptado de ABEEólica (2017a).

Gráfico 3 - Geração de energia eólica média (em MW) ao mês ao longo do ano de 2017.

É possível estimar que durante todo o ano 2017 o estado gerou em média 1.510,03 MW ao mês de energia eólica. Em relação ao ano 2016, em que se gerou em média 1.208,0 MW ao mês, o estado cresceu cerca de $25 \%$ em geração eólica.

O fator de capacidade de um parque eólico pode ser definido como a razão da potência real produzida durante um período dividida pela potência máxima durante esse mesmo período. Assim, uma vez que a energia gerada em um parque eólico é inferior à sua capacidade máxima em um certo período, o fator de capacidade reflete a qualidade dos ventos da região.

No Gráfico 4 são apresentados os valores para o fator de capacidade médio mensal durante todo o ano de 2017 medido no estado do Rio Grande do Norte. Dessa forma, é possível verificar que durante todo o referido ano o fator de capacidade médio do estado foi igual a $44,4 \%$. Isto significa que de toda a potência instalada em todos os parques eólicos do estado apenas durante $44,4 \%$ do tempo essa energia foi gerada.

Pode-se afirmar que a eficiência dos parques eólicos no Rio Grande do Norte está abaixo da média dos estados de Maranhão (68\%), Bahia $(48,5 \%)$, Pernambuco $(48,3 \%)$ e Piauí $(46,1 \%)$ conforme pode ser observado na Tabela 2 , que apresenta os valores do fator de capacidade médio ao longo do ano de 2017 para os estados do Nordeste. 


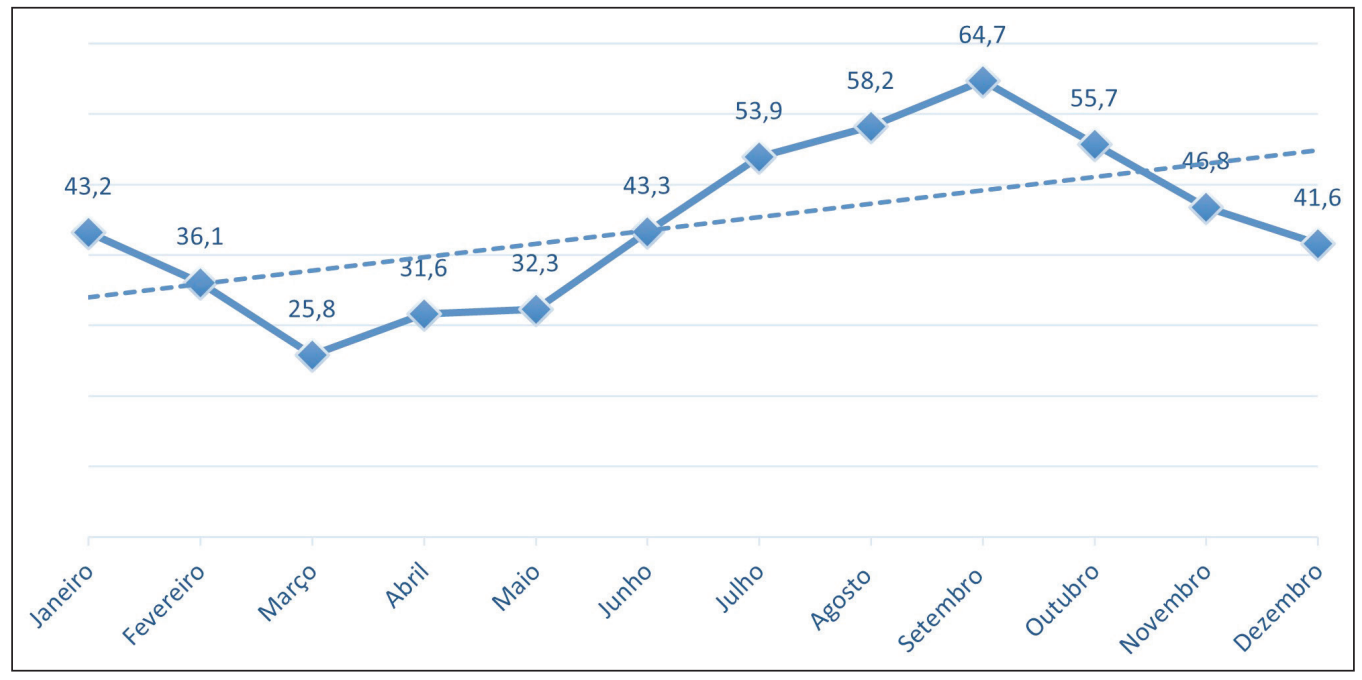

Fonte: Adaptado de ABEEólica (2017a).

Gráfico 4 - Fator de capacidade médio (\%) ao mês ao longo do ano de 2017.

Tabela 2 - Fator de capacidade médio durante 2017 nos estados nordestinos

\begin{tabular}{|c|c|c|}
\hline Posição & Estado & Fator médio (\%) \\
\hline $1^{\mathrm{a}}$ & Maranhão & 68,00 \\
\hline $2^{\mathrm{a}}$ & Bahia & 48,50 \\
\hline $3^{\mathrm{a}}$ & Pernambuco & 48,30 \\
\hline $4^{\mathrm{a}}$ & Piauí & 46,10 \\
\hline $5^{\mathrm{a}}$ & Rio Grande do Norte & 44,40 \\
\hline $6^{\mathrm{a}}$ & Rio Grande do Sul & 37,09 \\
\hline $7^{\mathrm{a}}$ & Ceará & 34,14 \\
\hline
\end{tabular}

Fonte: ABEEólica (2017a).

Apesar de ocupar a terceira posição em fator de capacidade, o estado potiguar se apresentou em 2017 mais promissor tanto quanto o Brasil, que teve um FC igual a 42,9\%, como quanto o mundo, que teve seu FC igual a $24,7 \%$ (ABEEólica, 2017a; GWEC, 2017).

Tanto os dados de geração de energia eólica como os dados do fator de capacidade demonstram a força dos ventos no território potiguar, em especial no período de estiagem, para a geração de eletricidade. Assim sendo, é possível operar os parques eólicos em sistemas complementares com as usinas hidrelétricas, de forma a preservar a água dos reservatórios em períodos de seca.

A energia eólica representa uma boa alternativa capaz de fortalecer o sistema elétrico do estado. Além disso, favorece a atração em investimentos produtivos, tais como a construção de parques eólicos para geração de eletrici- 
dade e de equipamentos componentes das turbinas eólicas, contribuindo assim para a geração de empregos e ao mesmo tempo com a preservação ambiental.

O mercado de energia eólica no estado potiguar está em plena expansão e ele se apresenta já bastante consolidado. Contudo, para uma expansão efetiva é necessária uma perfeita sintonia entre a produção e a distribuição dessa energia. Isto é, o ritmo de expansão da instalação de parques eólicos deve ser acompanhado na mesma medida pela construção de linhas de transmissão de modo a distribuir essa energia elétrica para a população.

$\mathrm{Na}$ prática se observa que faltam linhas de transmissão de energia para escoar a energia produzida nos parques eólicos. A falta de linhas de transmissão, devido ao atraso histórico de ampliação da infraestrutura elétrica, pode ser considerada como um dos principais gargalos para o aproveitamento mais eficiente do potencial eólico do estado do Rio Grande do Norte.

Assim, pode-se afirmar que a rede de transmissão atual não tem capacidade para escoar toda energia eólica produzida em território potiguar. Como consequência dessa inadequação da infraestrutura elétrica do estado é que ele apresenta fator de capacidade bem abaixo de outros estados nordestinos.

É importante destacar que no passado um projeto eólico era construído e podia ficar muito tempo parado por atraso na entrega de uma linha de transmissão para escoar sua produção. Para não amplificar esse problema, o estado poderá ter novos projetos eólicos adiados até que novas linhas de transmissão sejam licitadas, além disso, um novo projeto só vai a leilão se ele comprovar que há linha de transmissão para escoar sua produção.

Outro fator importante para propiciar o desenvolvimento do setor eólico no estado é a política estadual. Valentine (2010), Saidur et al. (2010), Abreu et al. (2015) e Lellis et al. (2018) advogam que uma política eficiente de diversificação de matriz energética depende de instrumentos capazes de permitir que a nova fonte tenha competitividade frente as consolidadas, ou seja, é preciso que o estado intervenha com tarifas feed-in, subsídios de capital, créditos fiscais para investimentos, negociação de certificados verdes, estímulos à contratação desta energia e investimento público em linhas de transmissão. Segundo a International Energy Agency (2015) somente com essas medidas o setor eólico consegue expandir sua participação e manter sua operação na maioria dos países.

\section{Considerações finais}

O estado do Rio Grande do Norte apresenta um expressivo potencial eólico, entretanto, o setor eólico ainda necessita de medidas eficientes que possibilitem a sua consolidação. Economicamente, a geração de renda, como consequência das instalações de parques eólicos, demonstra um papel relevante dos impactos positivos decorrentes do investimento em geração de energia eólica no Rio Grande do Norte.

Partindo-se da premissa de que os estados nordestinos sofrem cons- 
tantes estiagens, é possível afirmar que o uso da energia eólica pode ser uma garantia para a distribuição de eletricidade nas regiões afetadas. Entretanto, é necessária a criação de políticas, tanto federal como estadual, que possibilitem o incentivo à produção da energia eólica e de outras modalidades de energias renováveis.

\section{Referências}

ABEEÓLICA - Associação Brasileira de Energia Eólica. Boletim Anual de Geração Eólica 2017. 2017a. Disponível em: <http://www.abeeolica.org.br/wp-content/uploads $/ 2017 / 05 / 424$ Boletim_Anual_de_Geracao_Eolica_2016_Alta.pdf>. Acesso em: 9 out. 2018.

Dados Mensais - Dezembro/2017. 2017b. Disponível em: <http://www. abeeolica.org.br/wp-content/uploads/2017/09/Dados-Mensais-Dezembro.pdf>. Acesso em: 8 out. 2018.

Boletim Anual de Geração Eólica 2016. Disponível em: <http://abeeolica.org. br/wp-content/uploads/2017/05/424_Boletim_Anual_de_Geracao_Eolica_2016_ Alta.pdf>. Acesso em: 21 out. 2017.

ABREU, M. C. S. et al. Energia eólica e mudança climática: estratégias dos integrantes da cadeia de suprimento. Revista Brasileira de Gestão e Desenvolvimento Regional, v.11, n.3, p.329-52, 2015.

ALVES, J. J. A. Análise Regional da Energia Eólica no Brasil. Revista Brasileira de Gestão e Desenvolvimento Regional, v.6, n.1, p.165-88, jan.-abr. 2010.

ANEEL - Agência Nacional de Energia Elétrica. Atlas de Energia Elétrica do Brasil. 3.ed. Brasília - DF, 2008. Disponível em: <http://www2.aneel.gov.br/arquivos/pdf/ atlas3ed.pdf>. Acesso em: 12 dez. 2017.

AZEVEDO, F. F. et al. Novas estratégias de geração de energia no estado do Rio Grande do Norte - Brasil: O caso do setor eólico energético. In: III SIMPOSIO INTERNACIONAL DE HISTÓRIA DE LA ELECTRIFICACIÓN, Ciudad de México, México, 2015. Anais... Ciudad de México: digital, 2015.

BEZERRA, F. D.; SANTOS, L. S. dos. Potencialidades da energia eólica no Nordeste. Caderno Setorial ETENE, v.2, n.5, p.1-12, 2017.

CARNEIRO, F. O. M. et al. Investigation of possible societal risk associated with wind power generation systems. Renewable and Sustainable Energy Reviews, v.19, p.30-6, 2013.

COSERN - Companhia Energética do Rio Grande do Norte. Potencial eólico do estado do Rio Grande do Norte. Brasília - DF: Cosern/Aneel, 2003.

FERREIRA JÚNIOR, J. C. G.; RODRIGUES, M. G. Um estudo sobre a energia eólica no Brasil. Revista Ciência Atual, v.5, n.1, 2015.

FILGUEIRAS, A.; SILVA, T. M. V. Wind energy in Brazil - present and future. Renewable and Sustainable Energy Reviews, v.7, p.435-51, 2003. 
GWEC - GLOBAL WIND ENERGY COUNCIL. Global wind statistics 2017. 2017. Disponível em: <http://abeeolica.org.br/wp-content/uploads/2018/02/GLOBAL-WIND-STATISTICS-2017-1.pdf>. Acesso em: 21 out. 2018.

HAMDAN, A. et al. A review on the micro energy harvester in structural health monitoring (SHM) of biocomposite material for vertical axis wind turbine (VAWT) system: A Malaysia perspective. Renewable and Sustainable Energy Reviews, v.35, p.23-30, 2014.

IEA - INTERNATIONAL ENERGY AGENCY. Energy and Climate Change - World Energy Outlook Special Report 2015. Disponível em: <https://www.iea.org/publications/freepublications/publication/WEO2015SpecialReportonEnergyandClimateChange.pdf>. Acesso em: 21 out. 2018.

JONG, P. et al. Integrating large scale wind power into the electricity grid in the Northeast of Brazil. Energy, v.100, p.401-15, 2016.

JUÁREZ, A. A. et al. Development of the wind power in Brazil. Renewable and Sustainable Energy Reviews, v.39, p.828-34, 2014.

JUNG, C.; SCHINDLER, D. On the inter-annual variability of wind energy generation - A case study from Germany. Applied Energy, v.230, n.15, p.845-54, 2018.

LELLIS, M. et al. The Betz limit applied to Airborne Wind Energy. Renewable Energy, v.127, p.32-40, 2018.

LEUNG, D. Y. C.; YANG, Y. Wind energy development and its environmental impact: A review. Renewable and Sustainable Energy Reviews, v.16, p.1031-9, 2012.

LIRA, M. A. T. et al. Estimation of wind resources in the coast of Ceará, Brazil, using the linear regression theory. Renewable and Sustainable Energy Reviews, v.39, p.509-29, 2014.

MELO, E. Fonte eólica de energia: aspectos de inserção, tecnologia e competitividade. Estudos Avançados, v.27, n.77, p.125-42, 2013.

OEBELS, K. B.; PACCA, S. Life cycle assessment of an onshore wind farm located at the northeastern coast of Brazil. Renewable Energy, v.53, p.60-70, 2013.

PEREIRA, E. B. et al. The impacts of global climate changes on the wind power density in Brazil. Renewable Energy, v.49, p.107-10, 2013.

RIO GRANDE DO NORTE. Governo do Estado do Rio Grande do Norte. Secretaria de Desenvolvimento Econômico. Fundação de Apoio à Pesquisa no RN. Plano de Ação em Ciência, Tecnologia e Inovação do Estado do Rio Grande do Norte: 2011-2020. 50 f. Secretaria de Desenvolvimento Econômico, Fundação de Apoio à Pesquisa. Natal $\mathrm{RN}, 2011$.

RODRIGUES, M. V. S.; AQUINO, M. D. Estrutura legal da gestão das águas no Estado do Rio Grande do Norte. Revista de Gestão de Água da América Latina-REGA, v.10, n.1, p.17-28, 2013.

RODRIGUES, M. V. S. et al. Análise da eficiência na produção de energia eólica nos principais estados brasileiros produtores, por meio da aplicação de análise por envoltória de dados. Revista Tecnologia Fortaleza, v.36, n.1 e 2, p.18-33, 2015.

SHAMSHIRBAND, $S$. et al. Wind turbine power coefficient estimation by soft computing methodologies: Comparative study. Energy Conversion and Management, v.81, p.520-6, 2014. 
SAIDUR, R. et al. A review on global wind. Energy Policy. Renewable and Sustainable Energy Reviews, v.14, p.1744-62, 2010.

SILMAS, M.; PACCA, S. Energia eólica, geração de empregos e desenvolvimento sustentável. Estudos Avançados, v.27, n.77, p.99-115, 2013.

VALENTINE S. V. A step toward understanding wind power development policy barriers inadvanced economies. Renewable and Sustainable. Energy Reviews, v.14, p.2796$2807,2010$.

VOGEL, E. E. et al. A novel method to optimize electricity generation from wind energy. Renewable Energy, v.126, p.724-35, 2018.

RESUMO - Este trabalho tem como objetivo apresentar um panorama do setor de energia eólica do estado do Rio Grande do Norte (RN) entre o período de 2004-2017, mostrando a força do estado na geração de energia elétrica proveniente dos ventos. Para isso, foi realizado um amplo levantamento bibliográfico em materiais acadêmicos e páginas eletrônicas de órgãos oficiais deste setor. Observou-se que a energia eólica tem experimentado um exponencial e virtuoso crescimento no estado. Entre 2004 e 2017, a potência instalada saltou de 1,8 MW para 3.625,50 MW. Em relação à geração, o RN é responsável por $32,72 \%$ de toda a geração de energia eólica do país e $38,95 \%$ da região Nordeste, atingindo a marca de 13,24 TWh nos 133 parques eólicos fixados no estado. O RN possui fator de capacidade médio de geração de $44,4 \%$, ocupando a $5^{\circ}$ posição no ranking brasileiro, logo atrás dos estados do Maranhão (68\%), Bahia $(48,5 \%)$, Pernambuco $(48,3 \%)$ e Piauí $(46,1 \%)$. Apesar disso, o fator de capacidade de geração do RN é superior à média nacional (42,9\%) e global (24,7\%). Por fim, constatou-se que, embora o RN tenha experimentado um crescimento vertiginoso na geração de energia de origem eólica, ainda há um campo vasto para crescimento do setor, mas para isso, são necessários incentivos e ações federais e, sobretudo, estadual para que o RN desfrute do seu potencial máximo de geração de energia limpa em escala e preço competitivo frente às outras tecnologias de geração.

PALAVRAS-CHAVE: Energias renováveis, Potencial eólico, Parque eólico.

ABASTRSCT - The objective of this paper is to provide an overview of wind energy in the state of Rio Grande do Norte between 2004 and 2017, demonstrating the state's strength in electric power generation from wind. This objective is achieved through an extensive bibliographic survey of academic sources and websites of official wind energy organizations. Exponential growth of wind energy generation had been observed at this state. Between 2004 and 2017, installed capacity grew from 1.8 MW to 3,3625.50 MW. Rio Grande do Norte accounts for $32.72 \%$ of all wind energy generation in Brazil and for $38.95 \%$ in the Northeastern region, totaling 13.24 TWh with 133 wind farms established at the state. Rio Grande do Norte has an average generation capacity factor of $44.4 \%$, the 5 th position in the Brazilian ranking, behind the states of Maranhão (68\%), Bahia (48.5\%), Pernambuco (48.3\%), and Piauí (46.1\%). Despite this, the state's generation capacity factor is higher than the national average $(42.9 \%)$ and the global average (24.7\%). Although Rio Grande do Norte has experienced vertiginous growth in wind energy generation, there is much room for further growth. Federal and local governments must develop incentive policies for wind energy to ensure that Rio 
Grande do Norte will achieve its maximum potential of clean electricity generation at competitive costs compared to other energy sources.

KEYWORDS: Renewable energy, Wind potential, Wind farms.

Gerbeson Carlos Batista Dantas é mestrando na Universidade Federal Rural do Semiárido. @ - gerbeson_dantas@hotmail.com /

https://orcid.org/0000-0002-6662-5789.

Marcus Vinícius Sousa Rodrigues é professor doutor da Universidade Federal Rural do Semiárido.@ - marcus.rodrigues@ufersa.edu.br /

https://orcid.org/0000-0002-6666-8885.

Leonardo Magalhães Xavier Silva é professor mestre da Universidade Federal Rural do Semiárido. @ - leonardomxs@ufersa.edu.br / https://orcid.org/0000-0003-1633-8148.

Marisete Dantas de Aquino é professora doutora da Universidade Federal do Ceará. @- marisete@ufc.br / https://orcid.org/000-0002-4940-3607.

Antônio Clécio Fontelles Thomazé professor doutor da Universidade Estadual do Ceará. @ - clecio@larces.uece.br / https://orcid.org/0000-0003-4263-4194.

Recebido em 27.6.2019 e aceito em 16.10.2019.

I,II, III Universidade Federal Rural do Semi-Árido, Mossoró, Rio Grande do Norte, Brasil. Iv,V Universidade Estadual do Ceará, Fortaleza, Ceará, Brasil. 